\title{
Colonialismo y educación médica: ¿educare o educere?
}

\author{
Leonardo Viniegra-Velázquez* \\ Unidad de Investigación en Medicina Basada en Evidencias, Hospital Infantil de México Federico Gómez, Ciudad de México, México
}

\section{Resumen}

En este trabajo se recuperan las raíces latinas de la educación, educare y educere, y se muestran sus respectivas equivalencias con la educación pasiva y la educación participativa. Se da cuenta del predomino histórico de la educación pasiva (educare) y su implantación en los países colonizados. Se plantea que el papel de la educación pasiva en la reproducción de los rasgos degradantes de las sociedades actuales (ethos), como el individualismo, la pasividad política y la competitividad, es la razón de su predominio, así como su contribución al control de conciencias que encubre el colapso civilizatorio en curso. Con respecto a la educación médica, los influjos colonizadores revestidos de modernidad han perpetuado la educación pasiva; desde el Informe Flexner hasta las competencias profesionales. Se afirma que las mentes colonizadas son el mayor obstáculo al progreso de la educación médica. La educación participativa (heredera de educere) se sustenta en la crítica profunda y creativa, potencia cognoscitiva capaz de elaborar un conocimiento penetrante y liberador. Se argumenta que la cima de este tipo conocimiento son formas superiores de ser en lo espiritual, intelectual, moral y convivencial, que cristaliza al emprender proyectos vitales orientados a una descolonización efectiva, que permita aproximarse a sociedades inclusivas, pluralistas, justas y solidarias basadas en la progresión de los derechos humanos y comunitarios, así como en la revaloración y la preservación de la diversidad biológica del planeta.

Palabras clave: Colonialismo. Educare-educere. Educación pasiva. Educación participativa. Crítica. Educación médica. Descolonización.

\section{Colonialism and medical education: educare or educere?}

\section{Abstract}

This work recovers the Latin roots of education-educare and educere-and shows their respective equivalences with passive and participatory education. Also, it gives an account of the historical predominance of passive education (educare) and its implantation in colonized countries. It is proposed that the role of passive education in reproducing degrading features of today's societies (ethos) such as individualism, political passivity, and competitiveness, is the reason for its dominance, as well as its contribution to consciences' control that conceals ongoing civilizational collapse. Regarding medical education, modern colonizing influences have perpetuated passive education, from Flexner Report to professional competencies. Colonized minds are the biggest obstacle to medical education progress. Participatory education (educere's heir) is based on deep and creative critique, a cognitive power capable of developing a penetrating and liberating knowledge. It is argued that the summit of this kind of knowledge are superior forms of being, regarding spiritual, intellectual, moral, and coexistence

\section{Correspondencia:}

*Leonardo Viniegra Velázquez

E-mail: leonardo.viniegra@gmail.com
Fecha de recepción: 30-07-2020

Fecha de aceptación: 13-09-2020

DOI: 10.24875/BMHIM.20000234
Disponible en internet: 23-07-2021

Bol Med Hosp Infant Mex. 2021;78(4):306-317

www.bmhim.com 1665-1146/C 2020 Hospital Infantil de México Federico Gómez. Publicado por Permanyer. Este es un artículo open access bajo la licencia CC BY-NC-ND (http://creativecommons.org/licenses/by-nc-nd/4.0/). 
dimensions, crystallizing in vital projects aimed at effective decolonization, which allow approaching to inclusive, pluralistic, just, and solidary societies based on the progression of human and community rights, as well as on the re-evaluation and preservation of the planetary biological diversity.

Keywords: Colonialism. Educare-educere. Passive education. Participatory education. Critique. Medical education. Decolonization.

«Nuestras manos ya están libres, y todavía nuestros corazones padecen las dolencias de la servidumbre (...). La dominación arraiga en la médula de nuestros pueblos. Un pueblo ignorante es un instrumento ciego de su propia destrucción. (...) Es necesario un programa de educación popular que nos forme para la libertad, la justicia, lo hermoso (...) una educación que no nos enseñe a obedecer ni a imitar, sino a soñar, a imaginar, a actuar."

Simón Bolívar

Fragmentos del Discurso de Angostura, 1819

\section{Introducción}

Pensar en el colonialismo y sus efectos en la educación, incluida la de los médicos, remonta a un universo de ideas vasto e inabarcable. De ahí la necesidad de acotar. Para tal efecto, son pertinentes las raíces latinas de la educación: educare y educere ${ }^{1}$ (hoy ignoradas al momento de pensar en la educación). Estas raíces aluden a dos formas inversas de entender el proceso educativo y permiten caracterizar gran diversidad de prácticas educativas por su mayor o menor correspondencia con una u otra. Educare significa criar, nutrir, que equivale a «dotar de conocimientos» al alumnado, donde el proceso es de fuera hacia dentro y el protagonista es el docente. Educere -también exducere- significa extraer de dentro hacia fuera, e implica incitar y guiar al discente hacia su realización. Aquí el proceso es del interior al exterior y el educando es protagónico. Ambos delimitan un extenso panorama de reflexión que no ha sido superado y muestra cómo, desde lejanos tiempos, se pensaba de maneras tan contrastantes acerca de la formación de la niñez y la juventud: dos formas esencialmente distintas de entender la condición humana.

Se ha desarrollado otra bipolaridad con la teoría de la educación participativa de base epistemológica, cuyos inicios datan de hace más de tres décadas ${ }^{2}$. Estos extremos opuestos son, de un lado, el que desestima e inhibe la iniciativa del alumnado en la generación del conocimiento (opiniones propias sobre asuntos de interés) y favorece el consumo indiscriminado y acrítico de información ajena a sus intereses (educación pasiva); del otro, el centrado en propiciar, motivar y encauzar el protagonismo cognitivo de los educandos (educación participativa) ${ }^{3}$. Cabe aclarar que el encuentro con las raíces latinas de la educación es reciente. De ahí surge el asombro ante las claras coincidencias entre ambas bipolaridades, lo que ha sido uno de los motivos para realizar este trabajo: difundirlas a fin de que sean revaloradas en sus méritos esclarecedores y reconocerlas como antecedente de nuestras propuestas.

En este ensayo se argumentan razones históricas y sociales del predominio de la educación pasiva (equiparable a educare) en la práctica educativa en general y médica particular con énfasis en los países colonizados. Con respecto a la educación participativa (equiparable a educere) se analizan las implicaciones y consecuencias para la educación, el carácter anticolonialista y el papel decisivo en la realización de las potencialidades cognoscitivas del alumnado hacia la conformación de sujetos y colectividades que prioricen un mundo hospitalario e incluyente, a contrapelo de la degradación que arrastra al colapso civilizatorio.

\section{La educación a través de la historia}

Un primer paso en la valoración de la vigencia del pensamiento latino en educación es explorar su trascendencia histórica (en particular educere). Para tal propósito, una estrategia lógica es rastrear en el pasado este enfoque bipolar, ya que conocer acontecimientos pretéritos no solo es cuestión de enterarse de pormenores, sino que también supone contar con un criterio interpretativo que permita comparaciones y distinga similitudes y diferencias entre corrientes educativas sincrónicas o diacrónicas. Así, el proyectar una mirada retrospectiva con el binomio educare y educere se topa con una situación: en la mayoría de las obras dedicadas a la historia de la educación que describen y ordenan de manera cronológica múltiples corrientes y escuelas, educere está ausente y educare funciona como supuesto implícito de la generalidad. Es decir, esa bipolaridad latina no ha sido criterio relevante 
(diferenciador o clasificador) en la estructuración de la mayoría de las obras históricas de la educación, aunque se reconocen algunas excepciones, como $\mathrm{La}$ cuestión escolar. Críticas y alternativas ${ }^{4}$, que clasifica las críticas a la escuela tradicional por diferentes pensadores y pedagogos, la mayoría del siglo XX.

Tal omisión revela las siguientes cuestiones: los significados e implicaciones de educare, y sobre todo de educere, no han sido motivo relevante de reflexión o marco interpretativo de acontecimientos como para hacerse notar en las obras de historiadores o de corrientes educativas que hicieron historia; de la mano de lo anterior, resultan de escasa factibilidad los intentos de reconstrucción interpretativa del pasado de la educación bajo el enfoque de ambos vocablos latinos ante el vacío de datos consistentes; de la ausencia de educere es dable inferir un predominio tácito de lo correspondiente a educare en la mayoría de las corrientes y escuelas surgidas en la historia.

En suma, con sus implicaciones en la conformación de subjetividades reflexivas y propositivas, educere ha sido intrascendente en la historia, lo que revela la naturaleza política de la educación ${ }^{5}$ en su papel reproductor de las relaciones sociales predominantes ${ }^{6}$ en favor de los intereses dominantes de la época y de la sociedad de que se trate.

Con respecto a la historia reciente, la evidencia es contundente de que educare (alimentar, nutrir, que traducido en actos educativos equivale a «llenar de conocimientos» al transmitir, instruir, formar, capacitar 0 actualizar al discente, donde lo principal del proceso es de fuera adentro, la labor docente es determinante y el conocimiento del alumno es heterónomo) ha sido el enfoque predominante al entender y practicar la educación, aunque con variantes, intensidades y matices. Por el contrario, educere (extraer de dentro afuera, que corresponde, en términos educativos, a incitar, conducir o acompañar al sujeto en el desarrollo y la realización de las potencialidades que le son inherentes, donde el proceso es del interior al exterior y el protagonista es el alumnado, conocimiento autónomo), ha permanecido en silencio o ignorado.

\section{Colonialismo}

La pretensión de analizar y penetrar en los sistemas educativos de las sociedades actuales, a fin de caracterizarlos en lo esencial y compararlos, debe considerar de entrada algo ineludible: el colonialismo, cuyas huellas permiten trazar una línea de demarcación entre dos tipos de países, los colonizadores dominantes (principalmente los imperios europeos) y los colonizados sojuzgados (la gran mayoría de los países víctimas de la colonización). El colonialismo fue una forma de dominación con un cortejo de sometimiento, despojo y etnocidio de los pueblos originarios ${ }^{7}$. Aquí, «etnocidio» no solo se refiere a la eliminación total o parcial de una población que comparte un territorio, sino principalmente a la destrucción, en diferentes grados, de una cultura con todo lo que implica: conjunto de bienes materiales, espirituales y simbólicos de un grupo social transmitidos de generación en generación. Estos bienes incluyen la lengua, la religión, los mitos fundacionales, las tradiciones, los modos de vida, las costumbres, las artes y los saberes. Así, el colonialismo significó la división del mundo en dos tipos de naciones o países en relación jerárquica: colonizadores y colonizados. Los diversos movimientos independentistas de los colonizados en los siglos XIX y XX, si bien representaron la independencia política formal respecto a las metrópolis, no implicaron la desaparición de la relación jerárquica ni la independencia económica y cultural en el sentido antes anotado. El colonialismo se perpetuó hasta nuestros días como una forma de sujeción imperceptible, y por lo mismo irresistible, a través de la reproducción intergeneracional de «mentes colonizadas" (sin obviar movimientos descolonizadores de segunda generación que se multiplican en muchos países a partir de la resistencia y la organización de los pueblos originarios), cuyas fisonomías actuales oscilan entre dos modalidades: despreciar o negar la cultura autóctona ancestral al tiempo de sobrestimar o absolutizar la colonizadora, o permanecer en el rol colonizado de subordinación impuesto por la dominación al asumir su «inferioridad intrínseca»a.

Dentro de las implicaciones del colonialismo cabe particularizar respecto a los saberes de los pueblos originarios en lo que Santos designa como epistemici$d i o^{8}$, consistente en la descalificación y la supresión de los saberes tradicionales perpetradas por la imposición de un conocimiento extranjero con pretensiones de validez universal basado en el cristianismo y en el capitalismo incipiente que, con el tiempo, se constituyó en el paradigma moderno occidental: la mirada eurocéntrica del mundo universalizada9 ${ }^{\text {. La implantación }}$ del paradigma moderno occidental requirió del

\footnotetext{
a En palabras de Eduardo Galeano: «El colonialismo visible te mutila sin disimulo: te prohíbe decir, te prohíbe hacer, te prohíbe ser. El colonialismo invisible, en cambio, te convence de que la servidumbre es tu destino y la impotencia tu naturaleza: te convence de que no se puede decir, no se puede hacer, no se puede ser».
} 
establecimiento de la dicotomía entre modernidad y tradición, que permitió degradar ontologías de los pueblos originarios e invalidar sus saberes no occidentales como «tradicionales", y por tanto como «residuos de un pasado sin futuro ${ }^{10}$. Un ejemplo de la universalidad del paradigma moderno occidental es la idea de historia universal, en la que los periodos y líneas de tiempo (prehistoria, edad antigua, media, moderna y contemporánea) se basan en el devenir histórico europeo, desestimando lo no europeo. Otro ejemplo se manifiesta en la interpretación eurocéntrica del periodo colonial como fase de expansión de la civilización, que significó un paso necesario para "sacar del atraso y la oscuridad» a los pueblos bárbaros y llegó a su fin al culminar las gestas de independencia de las colonias americanas, africanas y asiáticas. Esta interpretación soslaya la principal característica de tal periodo desde la óptica de los sojuzgados: el despojo, el etnocidio y, especialmente, el epistemicidio. El paradigma moderno occidental se instauró como «la civilización occidental» porque la mayoría colonizada sobreviviente del etnocidio "se convenció» de la necesidad de abjurar de sus creencias y tradiciones primitivas, de abrazar la religión verdadera y la cultura superior, y de integrarse al progreso civilizatorio, lo que ha permanecido en el inconsciente y el imaginario colectivos de las poblaciones «independientes» como proclividad y receptividad acríticas de novedades provenientes de las metrópolis, que operan como influencias colonizadoras renovadas y perennes.

La dominación colonial no se habría consolidado sin la educación en su papel transformador de «los paganos en fieles a la religión y obedientes de los preceptos civilizatorios». Tal atentado ontológico perpetrado durante generaciones nunca culminó, como lo revela la pervivencia de remanentes de las culturas originarias en espacios marginales y clandestinos. El proceso de inculcación de los pueblos originarios, preñado de violencia simbólica y física, se hizo posible por la proliferación de centros evangelizadores que adoctrinaron a los naturales en la religión verdadera para su salvación, enseñarles oficios de servidumbre y dosificarles el remedio redentor de las "verdades universales", eje de la civilización occidental en esos tiempos.

Solo una mirada excéntrica al paradigma moderno occidental hace posible otra inteligibilidad del colonialismo ${ }^{11}$ y penetrar en el ethos de la nación que integramos, heredera de un coloniaje que favoreció la estratificación en castas, la esclavitud, el racismo, la corrupción, la opulencia sin freno, la pobreza sin fin, gobiernos subsidiarios de una monarquía expoliadora y autoritaria regida por dogmas punitivos y excluyentes. Con tan pesada herencia, la población, con marcadas desigualdades, diversa, sectaria, pasiva ante los asuntos públicos, racista, con propensión por lo extranjero y desdén por lo propio (con infinidad de excepciones), revela la pervivencia de nuestra condición colonizada y de subordinación e imitación de influencias colonizadoras. Así como el colonialismo requirió de la educación para consolidarse, la descolonización de mentes no será posible sin una educación liberadora basada en la crítica.

\section{Ethos de la civilización actual y la educación}

En la civilización occidental (que se arroga la universalidad) destacan tres caracteres como los más distintivos para entender el momento histórico que vivimos:

1) El «valor supremo» de la vida humana es el lucro sin límite y la ganancia a toda costa; lo que no contribuya a los buenos negocios, languidece o es inviable.

2) La dignidad humana es una mercancía en devaluación progresiva.

3) La codicia sin freno ha convertido en lucrativos el hambre, la miseria, la infamia, el tráfico de personas, las cárceles, las guerras, el terror o la destrucción del ecosistema.

Estas tendencias revelan un diagnóstico ineludible ${ }^{12}$ : «nuestro mundo, inmerso en una degradación omnímoda, es evidencia del agotamiento y la ruina de una civilización bajo el dominio implacable de los intereses de lucro sin límite, que ha convertido en mercancía lo más sublime y vil de la condición humana, y en rentables las peores atrocidades y la devastación planetaria». Se plantea ruina y no crisis porque asistimos al derrumbe de los valores dignificantes de la condición humana; es decir, la degradación está anclada en las entrañas de las subjetividades que la perpetúa (sin dejar de lado infinidad de grupos, organizaciones y pueblos originarios que resisten e insinúan otro mundo posible).

Si advertimos que el colapso civilizatorio resulta de un largo proceso de degradación acelerado en las últimas décadas, cabe preguntarse: ¿qué tipo de educación ha «coexistido pacíficamente» con la degradación hasta la debacle o, peor aún, ha sido permisiva y hasta cómplice? La respuesta es la educación pasiva, heredera de educare, que cumple su papel inculcador-reproductor de las ideas y prácticas imperantes de la 
cultura en turno, y convierte a los educandos en consumidores compulsivos y acríticos de información heterónoma que integran legiones de especialistas dóciles, explotables por un mercado de trabajo cada vez más restrictivo, injusto e inseguro. De este modo, la escuela, bajo la lógica del mercado, se afana por convertirse en fábrica eficiente de «mercancías competitivas» y reproducir la fuerza de trabajo actualizada y versátil que las empresas requieren. Así las cosas, es obvia la imposibilidad de este tipo de educación para neutralizar 0 contrarrestar las consecuencias de la dominancia de los intereses de lucro sin límite. De hecho, es una expresión palmaria de la degradación en curso que la aleja cada vez más de ese ideal nostálgico: «forjar las fuerzas liberadoras y de superación de la condición humana». En el mismo sentido, los enseñantes, al profesar las ideas y prácticas predominantes de su oficio (propias de la educación pasiva), son el eslabón clave en la perpetuación del ethos de una civilización en fase de agotamiento, cuyos rasgos más destacables, con muchas variantes e intensidades, son los siguientes ${ }^{12}$ :

1) Individualismo, que supone proyectos vitales de "cada quien lo suyo y sálvese quien pueda»; insensible y distante de los intereses colectivos y sus reivindicaciones, ajeno a acontecimientos que ocurren más allá del círculo cercano por más que sean graves atentados contra la dignidad más elemental. Según Bauman, en un mundo individualista, «la responsabilidad colectiva por los males de la sociedad no existe ${ }^{13}$.

2) Especialización reduccionista y excluyente, forma actual de la división del trabajo, en la cual el especialista con visión parcial, fragmentaria e inconexa no capta la raíz de los acontecimientos que le sacuden y afectan. Desinteresado por conocer su contexto histórico y social, genera distancia o aversión al pensamiento complejo e integrador, y vive sumergido en un mundo individualista que percibe oscuro, caótico e inseguro.

3) Pasividad ante los abusos de poder, cuya raíz son las limitaciones cognoscitivas (reduccionista y excluyente) que inmovilizan al especialista ante acontecimientos que juzga ajenos a sus intereses, a lo que se agrega la sumisión ancestral a la autoridad (culturas colonizadas), con actitudes predominantes de impotencia o dejación ante las adversidades, que han sido interiorizadas y se manifiestan en conformismo, fatalismo y evasión.

4) Competitividad exacerbada por un mercado de trabajo restrictivo e implacable que fomenta la desunión, la rivalidad, la desconfianza y el antagonismo (no la cooperación, la camaradería ni la solidaridad); además, hoy día, la autocompetencia y la autoexplotación han exacerbado el estrés laboral (síndrome de burnout), lo que acrecienta el abuso y la exclusión.

5) Consumismo insaciable, carné de identidad universal, para satisfacer deseos inducidos, desfogar angustias o mitigar ansiedades, sostén de una economía que profundiza las desigualdades, agota los recursos naturales y devasta el planeta.

6) Alta vulnerabilidad a la manipulación mediática por multiplicidad de asuntos que se ignoran, son indiferentes o escapan al entendimiento, enraizada en el individualismo y la especialización excluyente.

Tales rasgos que "se respiran en la atmósfera global» y son reproducidos por la escuela - por acción u omisión- se designan degradantes porque subyacen a la permisividad y la complicidad con el ánimo de lucro que precipita al colapso civilizatorio. Estos rasgos exhiben una marcada variabilidad entre colonizadores y colonizados: en los primeros, son consistentes, nítidos, acentuados y ampliamente generalizados (son originarios); en los segundos, son inconsistentes, atenuados o ausentes en multitud de organizaciones $y$, particularmente, en un buen número de pueblos y culturas originarias de la geografía planetaria que representan, en muchos casos, la reserva moral de la humanidad.

\section{Educare, educación pasiva}

La educación como proceso cuyo sentido fluye del exterior al interior del educando, donde el enseñante es protagonista como depositario del saber, el alumno es consumidor de información sin sentido y la memoria es la principal potencia cognoscitiva que se promueve y valora, incluye diversas modalidades a todos los niveles: alfabetizar, transmitir, instruir, informar, capacitar, especializar o actualizar, corresponden a educare y son característicos de la educación pasivab.

Este tipo de educación, que ha predominado en la historia con poder de exclusión de corrientes contestatarias - por su eficacia en el control de conciencias y cuerpos a favor de la dominación de los intereses hegemónicos de la sociedad-, ha permanecido casi

b El concepto de pasividad no se refiere a la mera receptividad o inacción de los alumnos; de hecho, pueden exhibir febril actividad. El punto clave es que, en su papel de consumidores de información, no desarrollan habilidades cognoscitivas para la búsqueda y la elaboración de su propio conocimiento. 
imperturbable ante la degradación extrema. Con anteojeras que hacen invisible el colapso civilizatorio, ha reproducido los rasgos degradantes y ha convertido la escuela en mera factoría de mercancías apetecibles («el capital humano») para un mercado explotador y excluyente. Estos caracteres de la educación pasiva muestran infinidad de variantes y matices a lo largo de la geografía, en especial las diferencias entre países colonizadores y colonizados. En los primeros, la lógica empresarial ha subordinado los ideales educativos, el negocio prima en la educación, avanza la privatización de lo público y se dispara el costo de la educación superior, acrecentando el elitismo y la exclusión. En los segundos, con marcadas desigualdades, si bien proliferan las instituciones privadas destinadas a minorías, la privatización sigue siendo tabú y el sometimiento a las leyes del mercado encuentra resistencias, sobre todo en los países con tradiciones educativas propias, como México.

\section{Educare en la educación médica}

Es en la educación médica de nuestro país donde el colonialismo ha tenido una presencia más reconocible y persistente. Al inicio de la colonización, la fundación de la Real y Pontificia Universidad de México (1551), con su Facultad de Medicina, instauró una educación que privilegia la teoría sobre la práctica y formaliza la exclusión académica de saberes empíricos basados en una robusta tradición herbolaria de los pueblos originarios que, no obstante, pervivieron en los remanentes comunitarios que escaparon del etnocidio y fueron preservados por las acciones de monjes ejemplares, sensibles y humanistas con la cultura sojuzgada y trato condescendiente con la población autóctona. Le siguieron sucesivas oleadas colonizadoras conforme surgían y se difundían nuevos saberes, técnicas, procedimientos y remedios de las metrópolis europeas, que reconfiguraban la práctica médica. Desde entonces, era claro el papel clave de la práctica en la formación de los médicos. Lo que modificara esta práctica tendría profundas repercusiones en su enseñanza; en otras palabras, la medicina que se aprende es la medicina que se practica. He aquí la mayor limitación formativa de la educación médica formal que aún permanece: primar las actividades de aula sobre el ejercicio clínico al asignar mayor crédito curricular a lo teórico que a lo práctico. Es decir, para la escuela, en los hechos, la teoría es lo más importante en la formación de los médicos y, por tanto, a mayor dominio teórico, mejor médico; este dogma es un remanente de la colonización.
Regresando a las oleadas colonizadoras, pero ahora a las del siglo XX, en especial la más influyente proveniente del vecino del norte: el Informe Flexner (1910), respecto a la situación de la educación médica en los Estados Unidos y Canadá ${ }^{14}$. Este informe, emanado del imperio que relevaría a los europeos, recomendaba la inclusión en el currículo médico de experiencias de aprendizaje en ambientes de laboratorio de las diferentes ramas de la ciencia (las Ilamadas ciencias básicas) durante los dos primeros años de la carrera de medicina, y los dos años restantes, en ambientes de hospital y escolarizados. Para justificar los cambios, se argumentó que dotarían a la enseñanza y la práctica médicas de reales bases científicas y, más aún, que legítimamente se podía hablar de la ciencia médica o de la medicina científica con la consecuente descalificación de medicinas empíricas o de tradiciones curativas como las orientales o la herbolaria. Aquí una precisión: las decisiones y las acciones preventivas, diagnósticas y terapéuticas y las recomendaciones higiénico-dietéticas pueden tener abundantes o escasas bases científicas; pueden ser individualizadas 0 genéricas, apropiadas o inapropiadas, oportunas 0 extemporáneas, eficaces o inútiles, beneficiosas o perjudiciales, pero en ningún caso pueden calificarse de «científicas».

La influencia del Informe Flexner significó una transformación curricular de la carrera de medicina que ha permanecido hasta ahora, mutatis mutandis, con esa misma organización que separa y desfasa lo básico de lo clínico. Lo que ha cambiado han sido los contenidos al desarrollarse las ciencias médicas, condicionando fragmentaciones, agregados, actualizaciones y, rara vez, integraciones. El punto clave de esta influencia colonizadora que significó más retroceso que avance fue el desfase temporal entre lo básico y lo clínico, lo que anuló la posibilidad de integrarlos y, por tanto, de conferirles sentido recíproco. Dicho de otro modo, para los estudiantes que aspiran a ejercer la medicina clínica (la gran mayoría), el estudio de las ciencias básicas adquiere sentido cuando aporta al entendimiento de los problemas clínicos de los pacientes, y la experiencia clínica refuerza su sentido cuando dispone de elementos esclarecedores de las ciencias básicas. El retroceso educativo consistió en dilapidar la energía vital del alumnado, al exigirle gran dedicación para estudiar y recordar información copiosa de escaso sentido, que deriva en aprendizaje fugaz que no deja huella y, lo más grave, que suele suscitar desinterés y hasta aversión a las ciencias básicas por parte de estudiantes que sufrieron para acreditarlas y evitar la 
exclusión. Es obvio que ese despropósito no es percibido porque es acorde a la lógica de un currículo rígido que sobrevalora la teoría en detrimento de la práctica, lo que constituye una manifestación nítida de la educación pasiva en medicina y un tributo a educare.

La formación de especialistas no difiere mayormente de lo arriba anotado, mantiene la disociación entre teoría y práctica y da primacía a lo teórico en los créditos curriculares; así, en las residencias médicas, las actividades de aula deben apegarse al programa y a la calendarización curricular, con independencia de los aconteceres clínicos relevantes del servicio de adscripción. Esto subraya que el posgrado no implica desarrollar potencias cognoscitivas superiores al pregrado; son las mismas: consumo, acumulación y recuerdo de información fragmentaria e inconexa, que es lo principal que se evalúa, pero esto no implica que los especialistas en ejercicio estén desprovistos de otras potencias como la investigación o la crítica, pues muchos las desarrollan y profundizan por cuenta propia (a menudo, a pesar de la escuela). Cabe aclarar que la disociación y el desfase teoría-práctica en la enseñanza de la medicina no nació al asumir dócilmente las recomendaciones del Informe Flexner, sino que datan del surgimiento de las universidades como descendientes de educare, donde los protagonistas del proceso educativo son los profesores, en su pretensión de «llenar de conocimientos» al alumnado.

Entre los incesantes influjos colonizadores que se sucedieron en el siglo pasado, se analiza la educación por competencias profesionales, la moda en turno. Lo primero a considerar es que su aceptación y popularidad no derivan, como suele afirmarse, de una superioridad comparativa sobre otros modelos que lo antecedieron o son coexistentes, sino de sus orígenes: el poder empresarial que, en la búsqueda de mayor competitividad de las corporaciones en la lucha encarnizada por el control de los mercados y la consecución de crecientes tasas de ganancia, requiere intensificar la explotación del trabajo (se emplean eufemismos como «productividad» y «eficiencia»); de ahí su incursión abierta y sin recato en la escuela ${ }^{12}$. Esa intromisión de la prepotencia empresarial para configurar el ámbito escolar a modo de sus intereses de lucro coincide con el auge del neoliberalismo, que implicó la desregulación de mercados y de actividades financieras, la ofensiva contra el trabajo al anular legislaciones y derechos y el desmantelamiento del estado de bienestar ${ }^{15}$, además de la consecuente privatización de servicios sociales como la educación y la salud, entre otros.
Las competencias profesionales, recubiertas con la aureola de progreso y aderezadas con atributos pedagógicos y humanísticos -que en rigor les son colaterales o ajenos- que confunden a legos, no dejan de ser una versión maquillada de educare y evidencia de nuestra condición colonizada. Aquí unos ejemplos de atributos "casi sobrehumanos» del egresado de estos programas ${ }^{16}$ : capacidad de pensamiento crítico, incongruente con un modelo que asume «verdades establecidas", máxime en sociedades "anestesiadas» por los medios de manipulación y persuasión; compromiso ético - por lo demás deseable en todo ciudadano-, inviable en una época mercantilizada al extremo, donde campean la corrupción y la simulación, y la dignidad humana es solo una mercancía devaluada; capacidad para generar nuevas ideas, inasequible en este modelo educativo que impone las verdades del momento y da primacía a lo técnico de las competencias (productividad y eficiencia) en un contexto histórico de sociedades sometidas al control de mentes y cuerpos por los medios de desinformación.

\section{Educere, educación participativa}

Recordemos que, según educere, el proceso educativo consiste principalmente en incitar, encauzar y acompañar a los educandos en el desarrollo y la realización de las potencialidades que les son inherentes. Cabe la pregunta: ¿a qué potencialidades aludiría lo enunciado hace tantos siglos? La respuesta es que se ignora, dado que educere ha estado prácticamente ausente en la historia de la educación. No obstante, si se piensa en la sabiduría ancestral ajena al reduccionismo actual, se puede adelantar que se trata de potencialidades cognoscitivas genéricas, como las que subyacen al dominio de cualquier tipo de actividad: filosófica, científica, artística, curativa, educativa, instrumental o de elaboración de objetos diversos.

A partir de tal consideración, se sigue una serie de preguntas, algunas acuciantes en este tiempo: ¿cómo lograr que la práctica inveterada de la educación pasiva vire a otra que incite y encauce a los educandos en la realización de sus potencialidades cognoscitivas?, ¿qué potencialidades son prioritarias a desarrollar para descolonizar mentes en una sociedad que aspira al progreso y la autodeterminación?, ¿cuáles para sobreponerse al control mediático apabullante basado en la desinformación? y ¿cuáles en la búsqueda de otro mundo posible, en tiempos de degradación extrema, con un planeta devastado y una civilización colapsada? 
La respuesta a la primera pregunta dio forma a la teoría de la educación participativa, cuya exposición muy condensada permitirá, además, responder de manera indirecta las demás interrogantes. De su versión más detallada y actual ${ }^{17}$ se destacará lo más relevante y pertinente, con algunas actualizaciones.

Lo primero es la base filosófica, la crítica de la experiencia, una ontología inédita: forma de ser en el mundo como aventura cognitiva sin término, pertrechada con la potencia cognoscitiva de la crítica (homo epistemicus). Esta arriesgada aventura inicia al surgir los intereses cognitivos por el sí mismo y el contexto, que se erigen en objetos centrales de la cognición: el sí mismo, por medio de la autocrítica, y el contexto, por la heterocrítica. No se trata de ensimismarse; el conocimiento inagotable del sí mismo y del contexto se estancaría y empobrecería sin adentrarse, por un lado, en el conocimiento de los otros y, en última instancia, de la humanidad; por el otro, más allá de lo inmediato, para proyectarse a ámbitos más vastos cuyo horizonte es el ecosistema planetario. Aquí una aclaración: la crítica de la experiencia no supone sabios omniscientes en una torre de marfil, sino apasionados por penetrar el mundo que les toca vivir al allegarse, por medio de la crítica, ideas esclarecedoras y actuar en consecuencia. Es decir, el conocimiento que no cristaliza en superiores formas de ser y actuar en lo espiritual, lo intelectual, lo moral y lo convivencial quedó trunco.

Al llevarlo a la práctica, lo filosófico de la educación participativa requiere precisar dos conceptos clave que hacen posible configurar espacios propicios para ejercer la crítica a fin de incitar y encauzar a los alumnos en la realización de sus potencialidades:

1) La experiencia vital, conjunto de vivencias del sujeto con alta "carga afectiva» derivadas de las interacciones con los objetos significativos ${ }^{c}$, es eje obligado de reflexión como vía de acceso al conocimiento del sí mismo y del contexto. Además, es fuente primaria de la afectividad, la fuerza para emprender aventuras riesgosas y superar adversidades. Cuando la reflexión introspectiva de la experiencia vital se orienta a reconocer la naturaleza de los vínculos y conflictos con el sí mismo y el contexto (autocrítica), se adentra en el conocimiento de ambos y, lo más importante, el sujeto se percata de que tal

c Estos objetos adquieren significado porque forman parte de la red de vínculos singulares del sujeto. Incluyen el sí mismo, familiares, amistades, compañeros de escuela, de trabajo, profesores o autoridades; también mascotas, obras de arte de todo tipo, lecturas de ciertos tópicos, rituales religiosos, objetos tecnológicos, espectáculos diversos y acontecimientos impactantes. conocimiento le permite concienciar inquietudes, preocupaciones, angustias, anhelos y aversiones, entender algunos porqués y actuar en consecuencia. Lo anterior deriva en estados anímicos cercanos a la serenidad, el sosiego y el entusiasmo por profundizar; es decir, al experimentar las bondades de la autocrítica, la carga de afectividad positiva la convierte en hábito y da forma a sus intereses cognitivos que vigorizan su empeño por captar la raíz de situaciones problema que le atañen, o sea, inicia su aventura cognitiva y el despliegue de sus potencialidades cognoscitivas ${ }^{17}$.

2) El sentido, en términos latos, alude al sentido de la vida, lo que hace que nuestra existencia sea digna de ser vivida, nos gratifique, nos satisfaga y nos infunda temple para actuar y sobreponernos a lo desfavorable. En la educación participativa, el sentido es una cualidad de los materiales de estudio (teorías, hechos, técnicas), de guardar sintonía y responder a los intereses cognitivos del sujeto y representar desafíos apropiados para profundizar. Esto plantea al docente el reto de seleccionar y secuenciar contenidos del curso con base en su sentido potencial (no se puede asegurar a priori la consecución del sentido) para los educandos, considerando su momento etario y su contexto sociocultural. Así, cuando el sentido está presente al realizar lecturas, tareas o proyectos, deriva en aprendizajes con sentido que se interiorizan y persisten, se integran en la experiencia vital, donde adquieren sinergia, se entrelazan para dar lugar a puntos de vista propios, sólidos y penetrantes y formas de proceder consecuentes.

Una vez precisados los conceptos clave para llevar adelante un proceso educativo propio de la educación participativa, lo siguiente es referirse a los aspectos medulares de la labor docente condensados en un aforismo ${ }^{18}$ : "La docencia realmente fecunda principia cuando "contagia entusiasmo" por entender quiénes somos y dónde estamos, y prosigue al procurar ambientes propicios para el ejercicio de la crítica profunda y creativa, que hace posible la elaboración de un conocimiento penetrante y liberador por parte de los educandos". Este aforismo prefigura una pedagogía insólita; alude, mutatis mutandis, a todos los niveles educativos, y es inédita por varias razones:

1) Especifica un papel docente diametralmente distinto del habitual, que enfatiza dos componentes:

- Incitar y motivar (contagiar el entusiasmo) a los alumnos para emprender su propia aventura cognitiva del sí mismo y del contexto, que supone desafiarlos con materiales cargados de 
sentido para sus intereses cognitivos, que solo se profundiza cuando la búsqueda se extiende hasta la humanidad (quiénes somos) y se proyecta para captar el ecosistema planetario (dónde estamos).

- Procurar ambientes propicios para ejercer la crítica, que devele otro derrotero a los educandos, donde se habitúan a reflexionar su experiencia vital, profundizan en asuntos de su interés (cargados de sentido), se ponen en tela de juicio, cuestionan lo que se da por sentado y, paso a paso, progresan en sus argumentaciones y puntos de vista en las discusiones y debates con sus pares, lo que confiere creciente penetración y alcance a la elaboración de su conocimiento.

2) Define un rol del alumnado - lejos de ser un consumidor ávido de información heterónoma desprovista de sentido, capaz de acumularla y recordarla cuando se le requiera- que protagoniza su propia aventura cognitiva y despliega sus potencialidades cognoscitivas, a condición de recuperar su experiencia vital como objeto central de reflexión y vía preferente del conocimiento del sí mismo y su contexto, y ser desafiado por ideas, puntos de vista y asuntos con sentido para sus intereses cognitivos, lo que les permite ejercer la crítica sistemática de los materiales de estudio (les atañen), desarrollarla y profundizarla al argumentar y contrastar sus puntos de vista en las discusiones y debates colectivos. De esta forma adquieren un carácter cuestionador y propositivo que les introduce en un sendero interminable de esclarecimiento colectivo que requiere proyectarse, en último término, a la humanidad y al ecosistema planetario. Esta lucidez cristaliza al asumir proyectos vitales empeñados en la superación de la condición humana, desde las más diversas perspectivas y los diferentes espacios laborales.

3) Plantea dos objetos de conocimiento prioritarios del proceso educativo: quiénes somos y dónde estamos, que son interdependientes y centrales en la aventura cognitiva. El primero aparece cuando la reflexión de la experiencia vital descubre el sí mismo y el contexto, cuya búsqueda de esclarecimiento da origen a los intereses cognitivos que se proyectan a colectividades de progresiva complejidad: la familia, la comunidad de pertenencia, la sociedad, la nación, el plano internacional... hasta la humanidad en su conjunto. El segundo, que también requiere el despliegue de los intereses cognitivos, implica su proyección al conocimiento del ambiente circundante inmediato y va escalando hasta alcanzar el ecosistema planetario ${ }^{19,20}$. Aquí una aclaración pertinente: el intento de penetrar objetos de conocimiento tan vastos como inagotables puede parecer un desafío inalcanzable; empero, no se trata de generar miríadas de hechos científicos (empirismo reduccionista) irrelevantes para captar la complejidad, sino de vivo interés por penetrar en la inefable complejidad del mundo que nos toca vivir, al allegarse, por medio de la crítica, ideas esclarecedoras para profundizar.

4) Reivindica la crítica como potencia cognoscitiva por excelencia, la cual, en pleno desarrollo, es una forma de pensar a manera de lógica metódica del proceso de cognición que, a diferencia de otras concepciones, pone el acento en dos aspectos del proceso. El primero, afín a la tradición filosófica: hábito de ponerlo todo en cuestión, de dudar de lo "comprobado o definitivo", de intentar llegar a la raíz de lo que parece "natural y evidente». El segundo alude al potencial creativo que confiere a la crítica su verdadero sentido: predisposición a idear, poner a prueba y proponer formas de pensamiento complejo (integrador, transdisciplinario) con mayor potencial esclarecedor de los desafíos cognitivos. Por tales énfasis se designa crítica profunda y creativa para distinguirla de acepciones comunes como lo descalificador o la censura. Esta forma de pensar, además de despertar del letargo ancestral a las potencialidades cognoscitivas - reprimidas secularmente-, les da forma de potencias efectivas y diversificadas ${ }^{7}$, capaces de liberar la mente de ideas y prejuicios que la constriñen, al adentrarse en quiénes somos y dónde estamos. Es decir, la crítica plena es un modo de pensar que posibilita la elaboración de un conocimiento penetrante y liberador $^{21,22}$, cuyo significado profundo son formas de ser superiores que resultan de cultivar cada una de sus cuatro dimensiones interdependientes: lo espiritual con la reflexión introspectiva; lo intelectual con la crítica profunda; lo moral con la ética, la historia, la honestidad o la honradez; y lo convivencial con actos dignificantes como educar, altruismo, respeto a lo diverso, solidaridad, lucha por la inclusión, la igualdad o la preservación de la biodiversidad.

Antes de retomar preguntas pendientes, cabe precisar que la teoría de la educación participativa representa un punto de llegada - no definitivo - de una elaboración perseverante; por tanto, no se propone como punto de partida para quien inicia su aventura, sino como horizonte posible. Respecto al tipo de 
potencialidades cognoscitivas prioritarias para neutralizar mentes colonizadas que nos subordinan a intereses ajenos, avanzar hacia otro mundo posible a contrapelo de la degradación y contrarrestar el poder mediático desinformativo que controla mentes y cuerpos al encubrir o maquillar la debacle, nuestra respuesta es categórica: solo una educación sustentada en la crítica profunda y creativa puede contribuir a la forja de humanos de un nuevo tipo (homo epistemicus), al dotarlos de un conocimiento penetrante y liberador, capaces de sobreponerse a los rasgos degradantes y generar, desde las más diversas trincheras, proyectos vitales convergentes cuyo horizonte son sociedades inclusivas, igualitarias, pluralistas, justas, solidarias, basadas en el respeto y la progresión de los derechos humanos y comunitarios, y en la revaloración y la preservación de la diversidad biológica del planeta.

\section{Educere en la educación médica}

Todo intento por acercar la educación participativa a la práctica educativa, al implicar una inversión de papeles de educadores y educandos, suscita resistencias por la incursión en territorios extraños, en especial en docentes rigidizados por años de cumplir rituales rutinarios y estereotipados impuestos verticalmente. Con respecto al alumnado, los más pequeños —ajenos a la pasividad- muestran gran disposición a participar al encontrar sentido a las tareas y actividades, se sueltan al opinar y argumentar sobre lecturas que les atañen y aprenden a escribir en su afán por relatar sus propias vivencias, inquietudes y preferencias ${ }^{21}$. Hace un cuarto de siglo nos dimos a la tarea de transformar el programa de formación de profesores del Instituto Mexicano del Seguro Social, dirigido a personal docente del área de salud ${ }^{22}$, como punta de lanza hacia la superación de la educación médica, con logros significativos, suplantados años después por las irresistibles modas foráneas. Cabe insistir en que implantar un tipo de educación radicalmente distinto del habitual debe tomar en cuenta que no se trata de todo o nada, sino de aproximaciones sucesivas, y que el dominio de la crítica y su pleno desarrollo es un proyecto de vida. De ahí las resistencias y obstáculos para iniciar y hacer avanzar la educación participativa en la educación médica ${ }^{d}$. Los estudiantes están habituados, por experiencias prece-

d Sin dejar de lado las objeciones del establishment donde se refugian mentes colonizadas dispuestas a defender los «avances de la modernidad» de acechanzas de "dudosa legitimidad y procedencia". dentes, a tediosos desafíos que la escuela impone para acreditar: consumir, acumular y recordar información heterónoma, fragmentaria, inconexa y con escaso sentido. Un paso clave en dirección a la educación participativa es la incitación sistemática a la reflexión de la experiencia vital —vivencias suscitadas en la atención de pacientes- y priorizar materiales de estudio con sentido para profundizarla, que es condición sine qua non para ejercer la crítica y desarrollarla. Las mentes colonizadas son el mayor lastre para superar la educación médica, atentas a incorporar los ropajes renovados de la educación pasiva procedentes del exterior y desestimar lo propio y, ahora mismo, deslumbradas por las competencias profesionales que son imposiciones del capital y exigencias del mercado.

\section{Epílogo}

Avanzar hacia una educación descolonizadora, que es condición de autodeterminación y verdadero progreso social, ya germinaba en el pensamiento de Simón Bolívar condensado en el epígrafe. No deja de asombrar que, jen 1819!, este prócer visionario tuviese tal nivel de conciencia y claridad del significado de la condición colonizada, de su persistencia en las mentes del pueblo liberado después de la independencia formal y, más aún, de la necesidad de otro tipo de educación como condición para hacer efectiva su liberación (considérese que las teorías del colonialismo surgieron a partir de la segunda mitad del siglo XX).

La educación participativa basada en el ejercicio de la crítica procura un conocimiento penetrante y liberador que, a partir del sí mismo y del contexto, se extiende y proyecta a la humanidad (quiénes somos), y al ecosistema planetario (dónde estamos) para actuar en consecuencia (qué hacer), y cuya expresión cimera son formas superiores de ser en lo espiritual, lo intelectual, lo moral y lo convivencial. No implica rechazar la especialización (forma actual de división del trabajo), sino desarrollar aproximaciones al propio quehacer, basadas en la complejidad (transdisciplinarias), que al revelar sus interrelaciones y complementos con otros permitan redefinir y priorizar los problemas a indagar e inciten la cooperación sinérgica, y lo decisivo, al concienciar su inserción en la espesa red de complicidades que converge en el real beneficiario de sus esfuerzos, los intereses de lucro sin límite («nadie sabe para quién trabaja»), pueda decidir, con conocimiento de causa, las condiciones futuras de realización de su labor. ¡Una ciencia sin ideas esclarecedoras está condenada a la servidumbre de las peores causas! 
Con respecto a la disyuntiva planteada en el título, ¿educare o educere?, se consideran los equivalentes de pasividad y participación para argumentar bajo dos perspectivas: la primera especifica las razones del predominio de la educación pasiva hasta nuestros días, que no obedece a una supuesta superioridad, sino a su contribución al control de conciencias y cuerpos que favorece la dominación de los intereses de lucro sin límite, que han degradado todo a su paso y han colapsado la civilización; y la segunda reivindica la vigencia de los postulados de educere y los lleva a sus últimas consecuencias para mostrar la necesidad de la crítica profunda y creativa como potencia cognoscitiva capaz de elaborar un conocimiento penetrante y liberador, que alcanza su plenitud al emprender proyectos vitales empeñados en erradicar la primacía del lucro como condición de una descolonización efectiva, que abra la posibilidad de acercarse a sociedades inclusivas, igualitarias, justas y solidarias, donde florezcan modos de vida respetuosa, estimulante, constructiva, serena y fraternal que integran la causa suprema de la experiencia humana: dignificación sublimada y universal de la vida en todas sus manifestaciones (un pensamiento utópico alusivo a la esencia del progreso humano).

Ahora una reflexión sobre las implicaciones de una educación universitaria descolonizadora, a propósito de la Clasificación Internacional de Universidades que ubica en la cima las universidades de élites opulentas, sustraídas del «mundanal ruido", ajenas a los problemas sociales, semilleros de pensamiento colonizador, reduccionista e hiperespecializado en diversas disciplinas, que operan como empresas que priman el lucro, innovan por encargo de las industrias tecnológicas de la dominación (militar, espacial, informática, cibernética, de la salud), cuyo mérito es su disfraz académico: elevada productividad (publicaciones y patentes) y numerosos premios Nobel (las designaremos universidades centrípetas). Este ideal de universidad ajeno a nuestras necesidades es un influjo colonizador que las mentes colonizadas revisten de autoridad incuestionable y las lleva a descalificar a las propias por su medianía o bajo nivel, y viceversa. Tal situación da pie a imaginar una universidad descolonizada de libre acceso, donde la crítica profunda y creativa sea efectiva, y el conocimiento penetrante y liberador haya originado una vinculación estrecha y diversificada entre su vitalidad creativa y las necesidades y carencias de la sociedad que la hace posible (la denominamos, por contraste, universidad centrífuga). De ahí sus características: núcleo pluralista, deliberativo, inquisitivo, cooperativo y propositivo que irradia a la sociedad que lo contiene como semillero de pensamiento crítico integrador y transdisciplinario que ilumine quiénes somos, dónde estamos, de dónde venimos y a dónde vamos; claustro de resguardo y renovación de las ciencias, las humanidades y las artes; promotor de los deportes; asesor colegiado de qué hacer y cómo hacerlo; conciencia crítica del ejercicio del poder del Estado; observatorio escrupuloso de problemas sociales, económicos, políticos y de justicia; fuerza movilizadora y acompañante de iniciativas colectivas de progreso social en todos los órdenes; laboratorio de innovación para subvenir necesidades colectivas y cuidar el ecosistema; vanguardia en la progresión de los derechos humanos y comunitarios; y esperanza de redención de comunidades menesterosas (pensamiento utópico sobre el papel de la educación en el progreso).

Así como el conocimiento penetrante y liberador se equipara, a nivel individual, a formas superiores de ser en lo espiritual, lo intelectual, lo moral y lo convivencial, a nivel universitario implica la búsqueda del progreso social, cuyo apogeo serían sociedades pluricéntricas, pluralistas, inclusivas, igualitarias, justas, deliberativas, autosuficientes, solidarias y vigilantes implacables del ejercicio del poder, donde la dinámica económica, en especial la cadena de investigación, innovación y desarrollo tecnológico, habría dejado de absolutizar el lucro so pena de desaparición, para priorizar su participación en la dignificación de la vida humana a través de sus dos puntales: la garantía y la progresión de los derechos humanos y comunitarios en sus múltiples facetas y el cuidado, la preservación y el fortalecimiento del ecosistema planetario.

Un último apunte: el viraje obligado por los tiempos pandémicos hacia la educación a distancia preludia la intensificación a largo plazo de la educación pasiva y una menor posibilidad de la participativa, lo que no obsta para perseverar en la conformación de ambientes propicios para el ejercicio y el desarrollo de la crítica como potencia cognoscitiva imprescindible en la búsqueda de un mundo hospitalario para todas las formas de vida, única garantía de dignificación humana.

\section{Responsabilidades éticas}

Protección de personas y animales. El autor declara que para esta investigación no se han realizado experimentos en seres humanos ni en animales. 
Confidencialidad de los datos. El autor declara que se han seguido los protocolos de su centro de trabajo sobre la publicación de datos de pacientes.

Derecho a la privacidad y consentimiento informado. El autor declara que en este artículo no aparecen datos de pacientes.

\section{Conflicto de intereses}

El autor declara no tener ningún conflicto de intereses.

\section{Financiamiento}

Ninguno.

\section{Bibliografía}

1. Wikipedia. Educación, etimología. (Última modificación 2 de julio de 2020.) Disponible en: https://es.wikipedia.org/wiki/Educaci\%C3\%B3n\#: :text=Etimol\%C3\%B3gicamente $\% 2$ C $\% 201$ a $\% 20$ palabra $\% 20$ $\%$ C2\%ABeducaci\%C3\%B3n\%C2\%BB,\%22conduzco\%2C\%20gu\%C3\%ADo\%22).

2. Viniegra Velázquez L. Los intereses académicos en la educación médica. Rev Invest Clin. 1987;39:281-90.

3. Viniegra Velázquez L. Hacia un nuevo paradigma de la educación. Rev Invest Clin. 2008:60:337-55.

4. Palacios J. La cuestión escolar. Críticas y alternativas. Barcelona: Laia; 1978.

5. Freire P. La naturaleza política de la educación. Barcelona: Paidós; 1990.
6. Bourdieu P, Passeron JC. La reproducción. Elementos para una teoría del sistema de enseñanza. Barcelona: Laia; 1979.

7. Santos BS. Introducción. En: Epistemologías del Sur (perspectivas). Madrid: Akal; 2014. p. 8

8. Santos BS. Más allá del pensamiento abismal: de las líneas globales a una ecología de saberes. En: Epistemologías del Sur (perspectivas). Madrid: Akal; 2014. p. 48.

9. Santos BS. Introducción. En: Epistemologías del Sur (perspectivas). Madrid: Akal; 2014. p. 15.

10. Santos BS. Introducción. En: Epistemologías del Sur (perspectivas). Madrid: Akal; 2014. p. 12.

11. Carnoy M. Teorías del colonialismo. La educación como imperialismo cultural. México: Siglo XXI; 1976. p. 65-77.

12. Viniegra-Velázquez L. La educación en nuestro tiempo: ¿competencia o aptitud? El caso de la medicina. Parte I. Bol Med Hosp Infant Mex. 2017:74:164-72.

13. Bauman $Z$. La vida líquida moderna y sus miedos. Tiempos líquidos. Vivir en una época de incertidumbre. México: Tusquets; 2013. p 13-8.

14. Flexner A. Medical education in the United States and Canada. A report to the Carnegie Foundation for the advancement of teaching. Part I. New York: Bulletin number four; 1910. p. 3-201.

15. Navarro V. Las consecuencias del neoliberalismo. Ataque a la democracia y al bienestar. Crítica al pensamiento económico dominante. Barcelona: Anagrama; 2015. p. 114-54.

16. Sánchez-Mendiola M, Duarte-Montiel I, Morales-López S, Lozano-Sánchez R, Martínez-González A, Graue-Wiechers E. Plan de estudios 2010 , Facultad de Medicina de la Universidad Nacional Autónoma de México. Gac Med Mex. 2011;147:152-8.

17. Viniegra Velázquez L. La educación y la crítica del conocimiento. Una perspectiva transdisciplinaria para entender la subjetividad y sus posibilidades cognitivas. México: Invipress-Hospital Infantil de México; 2015.

18. Viniegra-Velázquez L. La crítica y la educación médica. Parte I. Bol Med Hosp Infant Mex. 2018;75:327-37.

19. Lovelock J. Gaia. Una nueva visión de la vida sobre la tierra. España: Herman Blume; 1983.

20. Lovelock J. Las edades de Gaia. Una biografía de nuestro planeta vivo. Barcelona: Tusquets; 2000.

21. Aguilar Mejía E, Viniegra Velázquez L. Atando teoría y práctica en la labor docente. México: Paidós; 2003

22. Viniegra Velázquez L, Aguilar Mejía E. Hacia otra concepción del currículo. Un camino alternativo para la formación de docentes-investigadores. México: IMSS; 2003 